\title{
Board 62: Institutional Change Efforts to Improve the Environment for Both Instructors and Students in Foundational Engineering Courses
}

\section{Dr. Jacob R Grohs, Virginia Tech}

Jacob Grohs is an Assistant Professor in Engineering Education at Virginia Tech with Affiliate Faculty status in Biomedical Engineering and Mechanics and the Learning Sciences and Technologies at Virginia Tech. He holds degrees in Engineering Mechanics (BS, MS) and in Educational Psychology (MAEd, $\mathrm{PhD})$.

\section{Dr. David B Knight, Virginia Tech}

David B. Knight is an Associate Professor and Assistant Department Head of Graduate Programs in the Department of Engineering Education at Virginia Tech. He is also Director of International Engagement in Engineering Education, directs the Rising Sophomore Abroad Program, and is affiliate faculty with the Higher Education Program. His research tends to be at the macro-scale, focused on a systems-level perspective of how engineering education can become more effective, efficient, and inclusive, tends to be data-driven by leveraging large-scale institutional, state, or national data sets, and considers the intersection between policy and organizational contexts. He has B.S., M.S., and M.U.E.P. degrees from the University of Virginia and a Ph.D. in Higher Education from Pennsylvania State University.

\section{Ms. Michelle Soledad, Virginia Tech, Ateneo de Davao University}

Michelle Soledad is a PhD candidate in the Department of Engineering Education at Virginia Tech. Her research interests include faculty development and data-informed reflective practice. Ms. Soledad has degrees in Electrical Engineering (BS, ME) from the Ateneo de Davao University (ADDU) in Davao City, Philippines, where she continues to be a faculty member of the Electrical Engineering Department. She also served as Department Chair and was a member of the University Research Council before pursuing doctoral studies. Prior to joining ADDU in 2008, Ms. Soledad was a Senior Team Lead for Accenture, where she worked on and managed systems maintenance and enhancement projects.

\section{Dr. Homero Murzi, Virginia Tech}

Homero Murzi is an Assistant Professor in the Department of Engineering Education at Virginia Tech. He holds degrees in Industrial Engineering (BS, MS), Master of Business Administration (MBA) and in Engineering Education $(\mathrm{PhD})$. Homero has 15 years of international experience working in industry and academia. His research focuses on contemporary and inclusive pedagogical practices, industry-driven competency development in engineering, and understanding the barriers that Latinx and Native Americans have in engineering. Homero has been recognized as a Diggs scholar, a Graduate Academy for Teaching Excellence fellow, a Diversity scholar, a Fulbright scholar and was inducted in the Bouchet Honor Society.

\section{Natasha Smith, Virginia Tech}

Natasha is the Director of Enrollment Management for the College of Engineering as the Associate Director of Advising in the Department of Engineering Education, which is home to all General Engineering students. These dual roles allow Natasha the unique opportunity to understand and articulate viewpoints of both administration and students.

Natasha strives to implement innovative and systematic technological advances to academic advising and enrollment management. 


\section{Institutional Change Efforts to Improve the Environment for Both Instructors and Students in Foundational Engineering Courses}

\section{Project Overview}

Foundational courses taken during the first two years are critical to student success in engineering programs. It is no surprise that such courses can serve as barriers or gatekeepers to student progress through the undergraduate curriculum. Although the difficulty of the courses may be an intrinsic part of the content, often other features of the course delivery - such as large class environments or a few very high-stakes assessments - can further exacerbate these challenges. And especially problematic, past studies have shown that grade penalties associated with these courses and environments may disproportionately impact women (e.g., Matz et al., 2017). Institutions often turn to non-tenure track instructional faculty to teach multiple sections of foundational courses each semester. Although having faculty whose sole role is to provide quality teaching is an asset, benefits would likely be maximized when such faculty have clear metrics for paths to promotion, some autonomy and ownership regarding the curriculum, and overall job satisfaction. However, literature suggests that faculty, like students, note ill effects from large classes, such as challenges connecting and building rapport with students and having time to offer individualized feedback to students (Mulryan-Kyne, 2010).

This Institutional Transformation NSF IUSE project focuses on instructors of large foundational engineering students with the belief that by better understanding the educational environment from their perspectives, we can improve the quality of the teaching and learning environment for all engineering students. Our project regularly convenes faculty teaching an array of foundational courses for engineering (e.g,. mathematics, chemistry, mechanics, and physics) and uses insights from these meetings and individual interviews to identify possible leverage points where our project or the institution more broadly might affect change. Parallel to this effort, we have been working with data stewards on campus to gain access to institutional data (e.g., student course and grade histories, student evaluations of faculty teaching) to link and provide aggregate de-identified results to faculty to feed more information in to their decisionmaking. Through this project, we hope to demonstrate that regular engagement between faculty and institutional leaders around analyzed and curated data is essential to continuous and systematic improvement.

\section{Summary of Results}

Our project progress is summarized below across three specific efforts. The first effort reports on a Summer Summit on Large Foundational Engineering courses which involved wide-ranging discussions all aimed at producing a report of process and policy recommendations to be shared with university administrators. The second involves the creation of an Institutional Data Explorer dashboard which enabled instructors to explore data relevant to their department and courses which sparked further areas of study. The third involves status updates on data access and analysis of student perceptions of teaching data.

\section{Summer Summit}


We conducted a two-day Summer Summit with a cohort of instructors from foundational courses for engineering in July 2018. Participants engaged in a series of conversations related to teaching, understanding of students, supports and constraints in the instructional system, as well as topics related to performance metrics, promotion pathways, and evaluations of instructors.

\section{Policy and Process Recommendations Related to Admissions and Curriculum}

Participants pointed to a variety of constraints or ideas for further investigation related to admissions or curricular paths of students. Many of these ideas focused on the preparedness of students for classes and were brainstormed in the spirit of pre-empting challenging situations that they commonly observe students face. Additionally, participants provided some thoughts related to how to optimally spend time to best support students' additional review needs during outsideof-class time for activities such as office hours. From these discussions, the following priorities were identified which our project will investigate over the next year:

- Investigate the relationship between admissions decisions, math readiness scores, and student success in engineering.

- Investigate the connection between the AP course credit versus dual enrollment credit of first-time freshman students and student success in engineering.

- Investigate the role of pre-requisite and co-requisite courses in student success in engineering

\section{Policy and Process Recommendations Related to Course Coordination}

Because foundational courses for engineering have large enrollments, may courses are split into many sections with several faculty members teaching those sections. Programs typically have a course coordinator for such courses to ensure consistency. Participants had strong views on how the university can better support such roles. The following process or policy recommendations emerged from the Summit.

- Define and place bounds around expectations of the role.

The definition of course coordination varies considerably across contexts. Participants suggested that each program (or potentially at a higher level of a college or the university) generate a clear definition and set of expectations for this role prior to a semester.

- Set time expectations for the role and assign workload accordingly.

The participants also suggested that some tasks for this kind of role are often overlooked. For example, the amount of time it takes to write a common exam may be considered, but the amount of time it takes to vet that exam with colleagues is not considered. Participants suggested that programs take a comprehensive approach in calculating time expectations.

\section{Policy and Process Recommendations Related to Training}

One of the common conversation points during the summit related to training both new faculty members as well as graduate teaching assistants. In addition to being concerned about quality of the educational experience for students, participants pointed to training (or lack thereof) as a key element to help with extensive workload issues associated to these foundational courses. With a 
higher turnover rate of faculty holding instructor kinds of positions (relative to tenure-track roles), these courses in particular may face this issue more frequently than other courses.

- Graduate teaching assistants need intentional training.

- Scaffolding training through involvement or more experienced graduate teaching assistants can reduce the burden on faculty.

- Offer mentoring and support for new faculty members.

- Collate a list of university workshops or resources that are useful for supporting teaching.

\section{Policy and Process Recommendations Related to Teaching-focused Faculty Career Paths}

As teaching-focused promotion paths are still being developed by the university, we asked participants to provide their insights on the topic. Much like some of the other themes, we heard a lot about transparency and the need for clear processes.

- Clarify promotion pathways for different tracks of instructional faculty.

- Clarify metrics for advancement.

- Move away from an adjunct faculty model.

- Ensure everyone has an opportunity to share their views.

- Support the professional development of instruction-focused faculty.

\section{Institutional Data Explorer Dashboard}

Because a key component of our project involves leveraging institutional data to enable faculty and departments to make more informed decisions, a key project effort has been to make running simple analyses easier. To this end, we developed an interactive Shiny app using RStudio and the language R. An example of this is seen in Figure 1. 


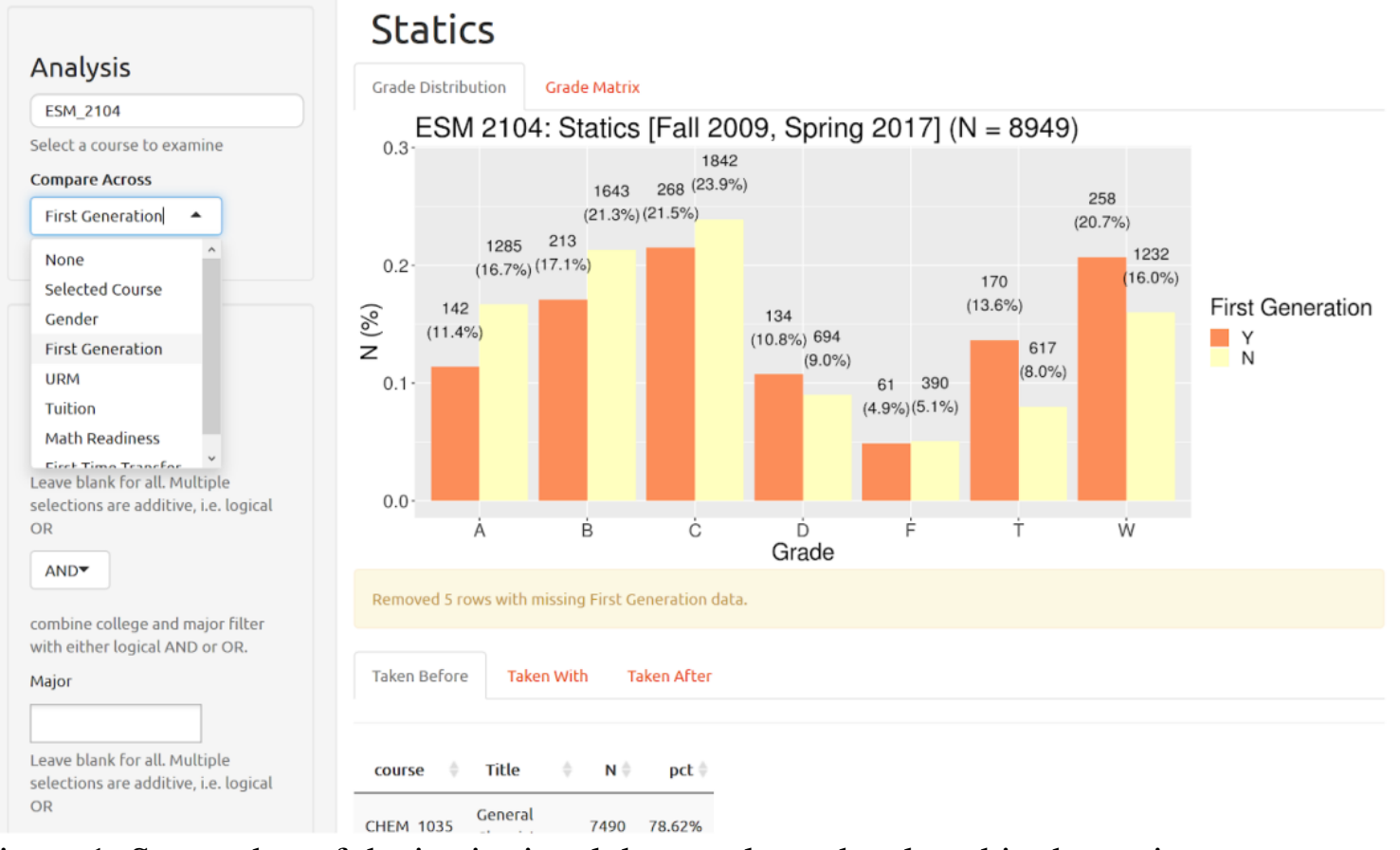

Figure 1: Screenshot of the institutional data explorer developed in the project

This interactive data explorer allows faculty of different departments to input a critical gatekeeping course and then explore student performance over time in the course across key demographics (e.g., first generation status as shown in Figure 1). Additionally, a second course (e.g., follow-on course for which the first course is a pre-requisite) can be used to see a crosstabulation of how grades in the first course distribute across grades in the follow-on course. This dashboard was used by instructors during the Summit to surface several other questions that the research team is now investigating. For example, we are exploring how performance in a course might vary depending on if the pre-requisite course credit was awarded through AP credit compared with either transfer from another institution or a traditional course-taking sequence within the institution.

While we found utility in this dashboard, our future work will involve discussing this dashboard in conjunction with key university stakeholders. During the course of our project, we discovered some units are paying for an outside company to do some similar analysis with a very easy and engaging interface but in many cases it is unclear what assumptions the outside company is making during the data analysis process.

\section{Institutional Data Access and Student Perceptions of Teaching}

Because a key component of our project involves leveraging institutional data to better the quality of the educational environment in large foundational engineering courses, one very important data stream is that of student perceptions of teaching end of semester course evaluations. While we recognize significant limitations of such data in the broader literature, our project is particularly interested in making productive use of this data since our institutions, like 
many others, invests significant energy in regularly collecting this data from students. Our rationale and plans are summarized below:

- Our project specifically works with a cohort of non-tenure track ranks (e.g., instructors, professors of practices, collegiate assistant professors) for whom quality of teaching is arguably even more critical than in the dossiers of tenure-track/tenured rank faculty. We feel it is important for us (as an institution) to understand these phenomena to put data in context and to continuously improve our measures of teaching quality. For example, it could be useful for an instructor and for departmental evaluators to know that some courses might be subject to systematic penalties because of the course itself (e.g., some of the more challenging required engineering courses) and not the unique instructor. Such comparisons could be useful, especially as these instructional faculty members move through promotion processes with dossiers populated almost exclusively by these high enrollment, gatekeeper courses which often have departmentally standardized assessments.

- Some instructors of large enrollment courses we have talked to have indicated interest in a way to make better sense of the massive amounts of qualitative comments they might receive on these course evaluations. With past work we have qualitatively coded responses and piloted some machine learning algorithms to identify most common themes. There is the potential to apply similar approaches to provide actionable feedback to the instructors that they may then use to improve the quality of the in-class instruction. Often these open-ended response sections can be the most useful for instructors, and developing a system for helping make sense of those data would further bolster understanding of these classes for both the instructor as well as the institution.

- There is significant discussion in the literature about inherent biases in student perceptions of teaching quality data (e.g., MacNell, 2015; Stark \& Freishtat, 2014). We would like to understand if these biases seem to be operating in our context. Potential investigations include the presence of gender biases but also may include understanding connections with student performance in the course, student performance in follow-on courses, and how that performance may (or may not) correlate with student perceptions of teaching. Past research from our team has indicated that faculty are very interested in knowing the degree to which student performance (now or in the future) correlates with course evaluation scores.

We have just recently gained access to this data and are working to perform the analyses discussed above. We look forward to discussing results of our progress in this arena on our poster at the ASEE conference.

\section{Acknowledgements}

This study is supported by a grant from the National Science Foundation's Division of Undergraduate Education: Improving Undergraduate STEM Education (Grant Number: NSFDUE-1712089). Any opinions, findings, and conclusions or recommendations expressed in this material are those of the author(s) and do not necessarily reflect the views of the National Science Foundation. 


\section{References}

MacNell, L. (2015). What's in a Name: Exposing Gender Bias in Student Ratings of Teaching. Innovative Higher Education, 40(4), 291-303. https://doi.org/10.1007/s10755-014-93134

Matz, R. L., Koester, B. P., Fiorini, S., Grom, G., Shepard, L., Stangor, C. G., ... McKay, T. A. (2017). Patterns of Gendered Performance Differences in Large Introductory Courses at Five Research Universities. AERA Open, 3(4), 2332858417743754. https://doi.org/10.1177/2332858417743754

Mulryan-Kyne, C. (2010). Teaching large classes at college and university level: challenges and opportunities. Teaching in Higher Education, 15(2), 175-185. https://doi.org/10.1080/13562511003620001

Stark, P., \& Freishtat, R. (2014). An evaluation of course evaluations. ScienceOpen Research. 